\title{
Obstructive jaundice causes reduced expression of polymorphonuclear leucocyte adhesion molecules and a depressed response to bacterial wall products in vitro
}

\author{
S Plusa, N Webster, J Primrose
}

\begin{abstract}
Background-Obstructive jaundice is associated with an increased incidence of infection and endotoxaemia, which may result from impaired host immunity. Neutrophil adhesion to vascular endothelium is a key part of the inflammatory response.

Aims-To investigate neutrophil adhesion molecule expression and activation in obstructive jaundice.

Patients-Nine adult patients with obstructive jaundice and 11 control subjects.

Methods-The expression of the neutrophil adhesion receptors L-selectin, CD11a, CD11b, CD11c, and CD15 was determined using flow cytometry. CD11b expression in response to stimulation with IMLP and endotoxin was measured.
\end{abstract}

Results-The basal expression of Lselectin, CD11a, and CD15 was significantly decreased in jaundiced patients $(p<0.05)$ and the expression of CD11b in response to stimulation with fMLP and endotoxin was significantly impaired in the jaundiced group. Endotoxin stimulation without plasma did not reverse the impaired response showing that it is not caused by endotoxin inactivation by plasma proteins.

Conclusions-Neutrophils from patients with obstructive jaundice show decreased adhesion receptor expression and an impaired response to stimulation with bacterial products. This cellular dysfunction may be responsible for the high incidence of septic complications in these patients.

(Gut 1996; 38: 784-787)

Keywords: cholestasis, neutrophils, endotoxin, sepsis, integrins, adhesion.

Academic Unit of Surgery

S Plusa

J Primrose

Intensive Care Unit N Webster

St James's University Hospital, Leeds

Correspondence to: Mr S M Plusa, Department of Surgery, The Medical School, University of Newcastle upon Tyne NE2 4HH.

Accepted for publication 31 October 1995

Infection causes considerable perioperative morbidity in patients with obstructive jaundice. ${ }^{12}$ Bacterial colonisation of the biliary tree is common $^{3}$ but changes in immune response may also be important. Kuppfer cell function $^{4}$ and delayed hypersensitivity ${ }^{5}$ are impaired in obstructive jaundice but human neutrophil function has not been investigated and animal studies have conflicting results. ${ }^{67}$ Neutrophil adhesion to the vascular endothelium is essential for subsequent transmigration $^{89}$ and congenitally impaired adhesion is associated with an increased incidence of bacterial infection.

The $\beta-2$ integrins CD11b and CD11a are responsible for firm adhesion, which is an essential prerequisite to migration out of the circulation. CD11b expression is increased by neutrophil stimulation and is a marker of neutrophil activation. The in vivo response to bacterial invasion is mediated by cytokines and the direct stimulation of neutrophils by bacterial wall products such as lipopolysaccharide (LPS) and fMLP, which will increase neutrophil CD11b expression. We have therefore studied the expression of neutrophil adhesion receptors from patients with jaundice and examined the response of CD11b to neutrophil stimulation by LPS and fMLP.

\section{Methods}

\section{Subjects}

Nine patients (four female) with obstructive jaundice were studied. Their mean age was 64 years (range 46-83), eight had malignant biliary obstruction and one had gall stones. Six had malignancy of the pancreas or biliary tree and two had obstruction due to nodes at the porta hepatis from metastatic colon carcinoma. They were compared with 11 control patients (five female) with benign, non-inflammatory disease and a mean age of 53 years (range 26-78). The mean bilirubin concentration in the jaundiced group was $258 \mu \mathrm{mol} / \mathrm{l}$ (range 84-597) and the mean duration of jaundice was four weeks (range 1-11). There was no evidence of clinical infection at the time of the study nor had there been any clinical episodes of infection during the course of their illness. All patients were studied before invasive investigations or surgery was carried out.

\section{Basal adhesion molecule expression}

Venous blood was taken into glass tubes with sodium heparin (10 units $/ \mathrm{ml}$ ) and analysed immediately. Aliquots of whole blood $(50 \mu \mathrm{l})$ were incubated on ice with fluorescein conjugated monoclonal antibodies to L-selectin (Leu-8, Becton-Dickinson UK, Oxford, UK), CD11a (MHM 24, Dako, High Wycombe, UK), CD11b (clone 44, Serotec, Oxford, UK), CD11c (KB90, Dako), CD15 core protein (C3D-1, Dako), and control fluorescein conjugated mouse IgG $_{1}$ (DAK-GO1, Dako), for 30 minutes. Lysing fluid (Becton- 
Figure 1: Neutrophils (granulocytes) identified by their characteristic properties of forward and side scatter by flow cytometry.

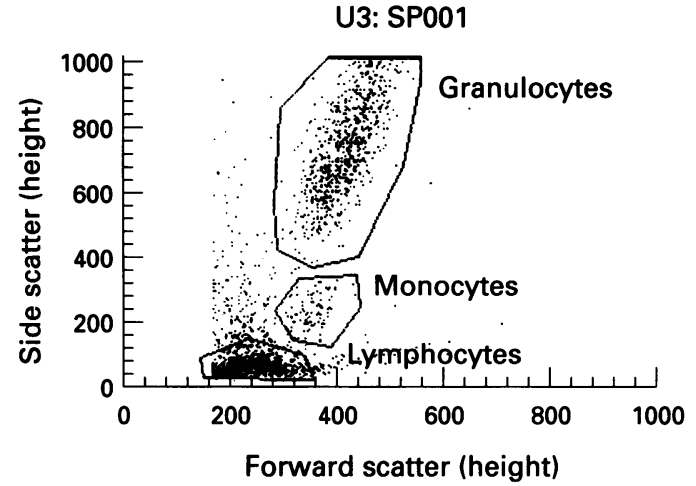

Dickinson) was then added and the tubes were incubated at room temperature for 10 minutes. They were then washed in phosphate buffered saline (PBS) containing azide $(0.05 \%)$ and resuspended in PBS-formaldehyde (1\%). Median channel fluorescence of the neutrophil population was determined by flow cytometry (FACSan, Becton-Dickinson, San Jose, USA). The neutrophil population was identified by their properties of forward and side scatter (Fig 1).

\section{$C D 11 b$ expression in response to stimulation}

The expression of $\mathrm{CD} 11 \mathrm{~b}$ in response to stimulation with fMLP (Sigma, Poole, UK) and LPS (Escherichia coli O26:B6, Sigma) was determined as follows. Whole blood $(0.5 \mathrm{ml})$ was incubated in endotoxin free tubes at $37^{\circ} \mathrm{C}$ with $10^{-6} \mathrm{M}$ and $10^{-8} \mathrm{M}$ fMLP or $100 \mathrm{ng} / \mathrm{ml}$ LPS. At various time points, $50 \mu \mathrm{l}$ aliquots were added to tubes containing fluorescein conjugated anti-CD11b and incubated as above. Aliquots were taken at $0,5,15$, and 30 minutes with $\mathrm{MMLP}$, and at $0,5,15,30,45$, and 60 minutes with LPS.

The effect of plasma proteins on the neutrophil response to LPS was investigated by spinning a sample of the heparinised whole blood for five minutes, removing the plasma, and resuspending the cells in an equivalent volume of Dulbecco's PBS-bovine serum albumin $2 \%$, containing calcium $(0.9 \mathrm{mmol} / \mathrm{l})$ and magnesium $(0.9 \mathrm{mmol} / \mathrm{l})$. The resuspended plasma free cells were then stimulated with LPS and CD1 $1 \mathrm{~b}$ expression determined at the same time points. Control samples were examined for CD11b expression at all time points after stimulation to examine the effects of rewarming and incubation on the neutrophils.

\section{Statistical analysis}

Statistical analysis was performed using the Mann-Whitney U test for unpaired comparison of non-parametric data and the Wilcoxon test for paired samples. The hospital clinical research (ethics) committee approved the study and all patients gave informed consent.

\section{Results}

Basal adhesion molecule expression L-selectin expression was significantly less in the jaundiced group (median channel fluorescence (MCF) 18.4, control 42.0, $\mathrm{p}<0.05$ ). The unstimulated expression of CD11a and CD15 was also significantly depressed in the jaundiced group (MCF CD11a 38.6, control $62 \cdot 7$, CD15 106, control 256, p<0.05). There was no difference in the unstimulated expression of CD11b (MCF 10.2, control 11.6) or CD11c (MCF 6·4, control 7·8).

\section{CD11b expression in response to stimulation}

CD11b expression in response to stimulation with IMLP and LPS was significantly less in the jaundiced group. Stimulation with $10^{-8} \mathrm{M}$ fMLP (Fig 2) produced significantly less CD11b expression at 15 and 30 minutes after stimulation with $10^{-6} \mathrm{M}$ fMLP the expression was significantly less at all time points (Fig 2). The response to LPS took longer to occur but at 45 and 60 minutes the response was also significantly less in the jaundiced group $(\mathrm{p}<0.05)$ (Fig 3). Single populations of neutrophils were seen at all time points (Fig 4).

The removal of plasma had no effect on CD1 $1 \mathrm{~b}$ expression in the jaundiced group, but the basal expression in the control group was significantly increased in the plasma free cells and this increase was significantly greater at all time points except 45 minutes. Stimulation with LPS without plasma did not affect the relation between the two groups. The expression of CD11b was significantly less at 45 and 60 minutes in the jaundiced group (Fig 3).

\section{Discussion}

The high morbidity associated with surgery and endoscopic cannulation of the biliary tree in obstructive jaundice remains a significant problem. Awareness of the risk of renal impairment related to perioperative systemic
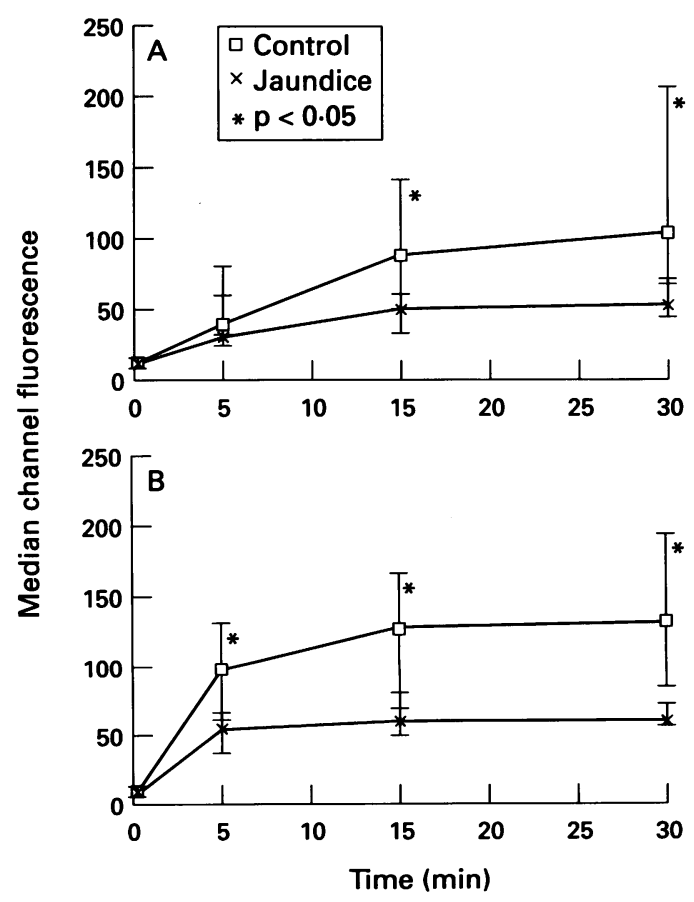

Figure 2: Neutrophil CD11b expression in response to stimulation with $(A)$ fMLP $10^{-8} M$ and $(B)$ fMLP $10^{-6} \mathrm{M}$. Medians and interquartile ranges shown. 


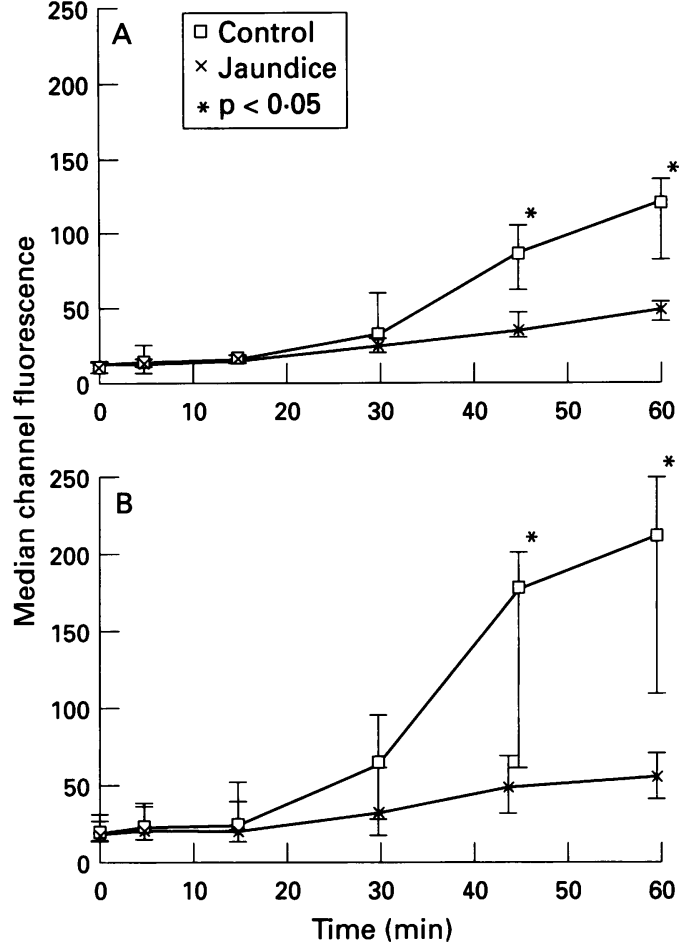

Figure 3: Neutrophil CD11b expression in response to lipopolysaccharide $100 \mathrm{ng} / \mathrm{ml}(A)$ with and $(B)$ without plasma. Medians and interquartile ranges shown.

endotoxaemia ${ }^{10}$ and the adoption of prophylactic measures such as oral bile salts or preoperative biliary drainage has limited the incidence of this complication but infection remains common. Cannulation of an obstructed biliary tree results in cholangitis in up to $25 \%$ of cases. ${ }^{11}$ The reason for the increased incidence of septic complications is unclear.

Neutrophils are a critical component of the response to infection and neutrophil adhesion is essential to allow localisation to the area of bacterial invasion. Adhesion occurs in two steps. The initial margination or 'rolling' of the neutrophil along the vessel wall is mediated by L-selectin and probably CD15 as a ligand for endothelial P-selectin. ${ }^{12} 13$ This is followed, if transmigration is to occur, by firmer adhesion mediated by the $\beta-2$ integrins, CD11a, CD11b, and CD11c. ${ }^{14}$ This study has shown abnormalities in neutrophil function in obstructive jaundice.

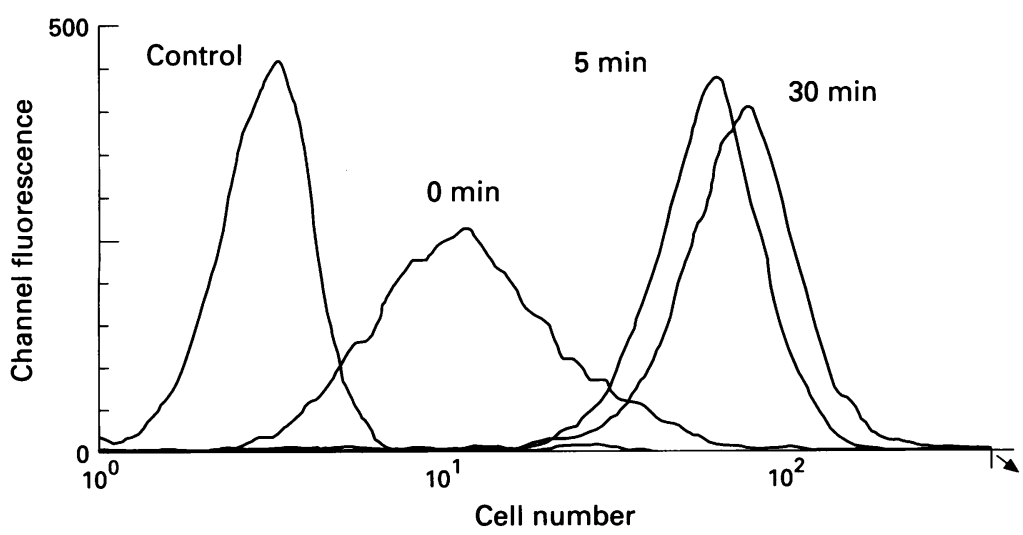

Figure 4: Neutrophil stimulation in response to the entire population. Overlaid histograms of the response to stimulation with $f M L P$.
The expression of L-selectin, CD11a, and CD15 was reduced in jaundice and thus both stages of the adhesion process may be affected. The antibody used against CD15 is for the core protein and is not specific for the sialylated form, which is more important in rolling. The importance of the actual level of expression of CD15 in rolling is not known. It is not possible therefore to draw definite implications on the functional effects of these changes. Bemelmans et al ${ }^{15}$ showed the presence of a persistent inflammatory response to obstructive jaundice evidenced by increased values of interleukin 6 and tumour necrosis factor $\alpha$. In vivo neutrophil stimulation might lead to increased CD11b expression and shedding of L-selectin. Though L-selectin values were reduced, the unstimulated expression of CD11b was unchanged. If an inflammatory response did lead to the activation of circulating neutrophils these may rapidly adhere and the cells obtained by venepuncture could represent a less active subset. None the less these results do not support the presence of activated neutrophils.

Human studies have shown impaired delayed hypersensitivity ${ }^{5}$ and Kuppfer cell phagocytosis. ${ }^{4}$ Animal studies have shown impaired hepatic clearance of bacteria ${ }^{16}$ and candida ${ }^{17}$ and impaired cellular immunity in rats. ${ }^{18}$ Jaundice has been shown in two studies to increase macrophage function in rats ${ }^{18}$ and mice ${ }^{15}$ but a third study showed decreased macrophage tumour necrosis factor $\alpha$, superoxide and nitric oxide production in response to endotoxin. ${ }^{19}$ The function of neutrophils, which with macrophages are the most important components of host defence against bacterial invasion, has not been extensively studied. Two studies in rats have produced conflicting results, one showed impaired peritoneal neutrophil chemotaxis in response to $\mathrm{fMLP}^{6}$ while the other showed normal chemotaxis but impaired phagocytic response. ${ }^{7}$

$\mathrm{CD} 11 \mathrm{~b}$ is a marker of neutrophil response to stimulation. It is stored intracellularly in granules that rapidly fuse with the cell membrane upon stimulation resulting in a rapid upregulation of receptor numbers, which is detectable by five minutes. ${ }^{20} \mathrm{CD} 11 \mathrm{~b}$ expression in response to stimulation is a sensitive marker of neutrophil activation. This study has clearly shown an impaired response to stimulation with bacterial products. LPS and fMLP activate neutrophils through different pathways. fMLP stimulates neutrophils directly by specific receptors on the surface membrane ${ }^{21}$ while the response to LPS is dependent on the circulating concentrations of plasma proteins. Bacterial permeability increasing protein, produced by neutrophils, inactivates LPS. ${ }^{22}$ Conversely the hepatic acute phase protein lipopolysaccharide binding protein greatly increases its activity. ${ }^{23}$ The response also depends upon the expression of its receptor CD $14 .^{24}$ This is shed on activation and is detectable in plasma ${ }^{25}$ where it may continue to bind LPS. Thus the cellular response to LPS is dependent upon a complex interaction of various circulating factors and cell receptor 
levels. The effects of plasma proteins were minimised by using a large dose of LPS at which the presence of protein ligands is less important, ${ }^{26}$ and part of the study was performed using plasma free cells. Unseparated cells were used to avoid the stimulatory effects that neutrophil isolation has on the expression of neutrophil adhesion receptors. ${ }^{27}$ An indirect stimulatory effect of LPS by monocyte cytokine secretion is possible in this model, but the effect of fMLP on the neutrophil is direct. This suggests decreased response at the level of the neutrophil itself.

The impaired neutrophil response to endotoxin agrees with the finding of impaired macrophage function. ${ }^{19}$ Jaundiced patients undergo episodes of endotoxaemia, which may result in subsequently impaired response to further stimulation. ${ }^{28}$ They have also been shown to have increased translocation of bacteria into mesenteric lymph nodes. ${ }^{19}$ This may be because of the absence of bile acids from the gut. A persistent inflammatory response as seen in mice ${ }^{15}$ could lead to increased interleukin 10 production, which would suppress both neutrophil and macrophage function and may be important. Another explanation for impaired function is the high incidence of neoplastic causes for jaundice. Most patients had disease limited to the hepatobiliary region but none the less malignancy and its associated catabolic state may well have significant effects on neutrophil function.

Removal of plasma had the effect of increasing neutrophil response to stimulation by LPS in the control group. The lack of effect in the jaundiced group may be further indication of hyporesponsiveness in jaundice but could also indicate suppression of control neutrophil function by a serum factor. Neutrophils are very sensitive to isolation procedures and it is possible that stimulation and priming occurs during centrifugation and resuspension. Removal of LPS binding proteins and soluble CD14 may also be important.

In summary this study has shown a defect in neutrophil function in obstructive jaundice in humans. These findings may explain the high incidence of localised sepsis in these patients. The impaired response to bacterial products, however, may also result in a relative resistance to the development of systemic sepsis with organ failure. It could therefore be of some benefit to a patient with jaundice.

Presented as an abstract at the British Society of Gastroenterology, Warwick, September 1993 (Gut 1993; 34 (suppl 4): S1).

1 Pain JA, Cahill CJ, Bailey ME. Perioperative complications in obstructive jaundice: therapeutic considerations. $\mathrm{Br} \mathscr{F}$ Surg 1985; 72: 942-5.

2 Wilkinson SP, Moodie H, Stamatakis JD, Kakkar VV, Williams R. Endotoxaemia and renal failure in cirrhosis and obstructive jaundice. $B M \mathcal{F} 1976 ; 2$ : $1415-8$.

3 Jackman FR, Hilson GRF, Lord Smith of Marlow. Bile bacteria with benign duct stricture. BMF 1980; 67: 329-32.

4 Drivas G, James O, Wardle N. Study of reticuloendothelial phagocytic capacity in patients with cholestasis. $B M \mathcal{F}$ phagocytic capacity
5 Cainzos M, Alcalde JA, Potel J, Puente JL. Hyperbilirubinaemia, jaundice and anergy. Hepatogastroenterology 1992; 39: 330-2.

6 Andy jr OJ, Grogan JB, Griswald JA, Scott-Conner CE. Peritoneal neutrophil chemotaxis is impaired in biliary obstruction. Am Surg 1992; 58: 28-31.

7 Roughneen PT, Droth DB, Kulkarni AD, Kumar SC, Andrassy RJ, Rowlands BJ. Inflammatory cell function in young rodents with experimental cholestasis: investigation of functional deficits, their cause, and their reversibility. of Pediatr Surg 1989; 24: 668-73.

8 Von Andrian UH, Hansell P, Chambers JD, Berger EM, Ton Andrian UH, Hansell P, Chambers JD, Berger EM,
Torres Filho I, Butcher EC, et al. L-selectin function is Torres Filho $\mathrm{I}$, Butcher EC, et al. $\mathrm{L}$-selectin function is at physiological shear rates in vivo. Am f Physiol 1992; 263 (4 Pt 2): H1034-44.

9 Furie MB, Tancinco MC, Smith CW. Monoclonal antibodies to leukocyte integrins $\mathrm{CD} 11 \mathrm{a} / \mathrm{CD} 18$ and CD11b/CD18 or intercellular adhesion molecule-1 inhibit chemoattractant-stimulated neutrophil transendothelial migration in vitro. Blood 1991; 78: 2089-97.

10 Evans HJR, Torrealba V, Hudd C, Knight $M$. The effect of preoperative bile salt administration on postoperative renal function in patients with obstructive jaundice. $B r \mathcal{F}$ Surg 1982; 69: 706-8.

11 Lai ECS, Mok FPT, Fan ST, Lo CM, Chu KM, Liu CL, et al. Preoperative endoscopic drainage for malignant al. Preoperative endoscopic drainage for m
obstructive jaundice. Br F Surg 1994; 81: $1195-8$.

12 Paavonen T, Renkonen R. Selective expression of sialylLewis $\mathbf{x}$ and Lewis a epitopes, putative ligands for $\mathrm{L}$ selectin, on peripheral lymph-node high endothelial venules. Am F Pathol 1992; 141: 1259-64.

13 Lund-Johansen F, Olweus J, Horejsi V, Skubitz KM, Thompson JS, Vilella R, et al. Activation of human phagocytes through carbohydrate antigens (CD15, sialyl-CD15, CDw17, and CDw65). F Immunol 1992; 148: 3221-9.

14 Springer TA. Traffic signals for lymphocyte recirculation and leukocyte emigration: the multistep paradigm. Cell 1994; 76: 301-14.

15 Bemelmans MHA, Gouma DJ, Greve JW, Buurman WA. Cytokines tumour necrosis factor and interleukin-6 in
experimental biliary obstruction in mice. Hepatology 1992 ; 15: $1132-6$.

16 Karz S, Grosfeld JL, Gross K, Plager DA, Ross D, Rosenthal RS, et al. Impaired bacterial clearance and trapping in obstructive jaundice. Ann Surg 1984; 199: 14-20

17 Katz S, Merkel GJ, Folkening WJ, Rosenthal RS, Grosfeld $\mathrm{JL}$. Impaired clearance and organ localisation of Candida albicans in obstructive jaundice. $\mathcal{F}$ Pediatr Surg 1991; 26: 904-6.

18 Greve JW, Gouma DJ, Soeters PB, Buurman WA. Suppression of cellular immunity in obstructive jaundice is caused by endotoxins: a study in germ-free rats. is caused by endotoxins: a study

19 Reynolds JV, Murchan P, Redmond HP, Watson RWG, Leonard N, Hill A, et al. Failure of macrophage activation in experimental obstructive jaundice: association with bacterial translocation. Br f Surg 1995; 82: 534-8.

20 Yong KL, Rowles PMK, Patterson G, Linch DC. Granulocyte-macrophage colony-stimulating factor induces neutrophil adhesion to pulmonary vascular endothelium in vivo: role of beta 2 integrins. Blood 1992; 80: 1565-75.

21 Burkey TH, Webster RO. Adenosine inhibits fMLP-stimulated adherence and superoxide anion generation by human neutrophils at an early step in signal transduction. Biochem Biophys Acta 1993; 1175: 312-8.

22 Biochem Biophys Acta 1993; 1175: 312-8. $\mathrm{MB}$, Scott RW. The role of bactericidal/permeability$\mathrm{MB}$, Scott RW. The role of bactericidal/permeabilityincreasing protein as a natural inhibit
toxin. $\mathcal{F}$ Immunol 1992; 148: 532-7.

23 Worthen GS, Avdi N, Vukajlovich S, Tobias PS. Neutrophil adherence induced by lipopolysaccharide in vitro. Role of plasma component interaction with lipopolysaccharide. $\mathcal{F}$ Clin Invest 1992; 90: 2526-35.

24 Wright SD, Ramos RA, Hermanowski-Vosatka A, Rockwell P, Detmers PA. Activation of the adhesive capacity of CR3 on neutrophils by endotoxin: dependence on lipopolysaccharide binding protein and CD14. F Exp Med 1991; 173: 1281-6.

25 Krüger C, Schütt C, Obertacke U, Joka T, Müller FE Knöller J, et al. Serum CD14 levels in polytraumatized and severely burned patients. Clin Exp Immunol 1991; 85: and severely

26 Dentener MA, von Asmuth EJU, Francot GJM, Marra $M N$, Buurman W. Antagonistic effects of lipopolysaccharide binding protein and bactericidal/permeabilityincreasing protein on lipopolysaccharide-induced cytokine release by mononuclear phagocytes. $f$ Immunol 1993; 151: 4258-65.

27 Kuijpers TW, Tool ATJ, van der Schoot CE, Ginsel LA, Onderwater JJM, Roos D, et al. Membrane surface antigen expression on neutrophils: a reappraisal of the use of surface expression on neutrophils: a reappraisal of the use of surface markers for neutrophil activation. Blood 1991; 78: 1105-11.
Mathison JC, Virca GD, Wolfson E, Tobias PS, Glaser K Uathison JC, Virca GD, Wolfson E, Tobias PS, Glaser K, Ulevitch RJ. Adaptation to bacterial lipopolysaccharide controls lipopolysaccharide-induced tumour necrosis factor production in 